EXTENDED REPORT

\title{
Anti-citrullinated peptide antibodies may occur in patients with psoriatic arthritis
}

\author{
B Vander Cruyssen, I E A Hoffman, H Zmierczak, M Van den Berghe, E Kruithof, \\ L De Rycke, H Mielants, E M Veys, D Baeten, F De Keyser
}

Ann Rheum Dis 2005;64:1145-1149. doi: 10.1136/ard.2004.032177

See end of article for authors' affiliations

.......................

Correspondence to: Bert Vander Cruyssen, Department of

Rheumatology, De

Pintelaan 185, Ghent

University Hospital, B-

9000 Gent, Belgium; bert.

vandercruyssen@ugent.be

Accepted 2 January 2005

Published Online First

4 February 2005
Background: Anti-cyclic citrullinated peptide (anti-CCP) antibodies are considered highly specific markers of rheumatoid arthritis. Despite the high specificity of the test, anti-CCP antibodies have also been observed in psoriatic arthritis.

Objective: To determine the frequency of anti-CCP antibodies in psoriatic arthritis and to describe the clinical characteristics of such patients.

Methods: Serum samples from 192 patients with psoriatic arthritis were analysed for anti-CCP antibodies. A previously defined cut off point was applied at a specificity level of $\geqslant 98.5 \%(42 \mathrm{U} / \mathrm{ml})$. Antibodies against pepA and pepB (two synthetic citrullinated peptides) were determined on samples containing antiCCP antibodies by line immune assay. The swollen joint count and the numbers of affected joints (present or past) were recorded. Clinical features were noted and if available radiographs of hands and feet were scored for erosions. Rheumatoid factor was determined in all samples.

Results: Anti-CCP antibodies were found in 15 patients (7.8\%); 13 of 15 anti-CCP2 positive samples were also positive for anti-pepA or pepB antibodies. The prevalence of anti-CCP antibodies was higher than expected in view of the highly specific cut off applied in the test. Detailed analysis of the clinical and radiological features makes it improbable that the high prevalence of anti-CCP antibodies resulted solely from concomitant psoriasis and rheumatoid arthritis or from misclassification.

Conclusions: Anti-CCP antibodies may be present in patients with psoriatic arthritis. Although some of the present cohort could have had psoriasis with concomitant rheumatoid arthritis, a proportion at least had the typical characteristics of psoriatic arthritis as the primary diagnosis.
$\mathrm{P}$ soriatic arthritis is a type of inflammatory joint disease in which axial or peripheral arthritis is associated with psoriasis. The picture of psoriatic arthritis is broad and comprises oligoarticular or polyarticular peripheral arthritis and axial involvement. ${ }^{1}$ Psoriatic arthritis shares features of spondyloarthropathies and rheumatoid arthritis. Evolution from oligoarticular disease to polyarticular disease has been described. ${ }^{2}{ }^{3}$ McGonagle et al suggested features of psoriatic arthritis that are helpful in distinguishing it from rheumatoid arthritis. ${ }^{4}$ These comprise the following: asymmetrical oligoarticular disease predominantly of the lower limbs, distal interphalangeal joint (DIP) involvement, enthesitis, dactylitis, typical radiological features (pencil-in-cup phenomenon, ankylosis of small hand or feet joints, arthritis mutilans (fig 1)), radiological sacroiliitis, and inflammatory low back pain. The broad spectrum of the disease makes it difficult to develop good criteria for diagnosis and classification. Although different criteria have been suggested, none are widely accepted..$^{2}{ }^{5-9}$ At present an international multicentre validation of diagnostic criteria is under way. ${ }^{8}$

Anti-cyclic citrullinated peptide (CCP) antibodies are antibodies against synthetic citrullinated peptides and are specific markers of rheumatoid arthritis. They belong to a group of anti-citrullinated protein/peptide antibodies (ACPA). Rheumatoid sera were found to contain antibodies that were detected by indirect immunofluorescence in rat oesophagus (the so called anti-keratin antibodies) ${ }^{10}$ or in human buccal mucosal cells (the so called anti-perinuclear factor), and on western blotting of human epidermis (antifilaggrin antibodies). ${ }^{11}$ This reactivity was found to be critically dependent on the presence of epitopes containing the amino acid citrulline ${ }^{11}$ Based on this knowledge, other assays were developed using synthetic citrullinated peptides such as CCP, ${ }^{12}{ }^{13}$ peptide A (pepA), and peptide B (pepB). ${ }^{14}{ }^{15}$ The anti-CCP enzyme linked immunosorbent assay (ELISA) is a more widely available test, based on citrulline containing peptides derived from filaggrin and later improved by screening dedicated peptide libraries. ${ }^{13}{ }^{15-20}$

Despite the described high specificity of the anti-CCP test, we and others ${ }^{19}$ have identified patients with psoriatic arthritis who are positive for anti-CCP antibodies. Based on these observations, we analysed a large group of patients diagnosed by their treating rheumatologist as having psoriatic arthritis, based on the presence of psoriasis with arthritis. We have assessed the prevalence of anti-CCP antibodies in these cases and described in detail their clinical and radiological characteristics in order to determine whether they can be considered genuine cases of psoriatic arthritis.

\section{METHODS}

\section{Patients and characteristics}

We included patients with skin or nail psoriasis who also had spondylitis or peripheral arthritis, and in whom serum samples had been sent to the laboratory of the department of rheumatology for routine work up. Spare serum was available from 192 patients. The study was approved by the local ethics committee. Patient and disease characteristics of all 192 patients included in the study are given in table 1 .

Abbreviations: ACPA, anti-citrullinated protein/peptide antibodies; CCP, cyclic citrullinated peptide; DIP, distal interphalangeal joint; ESSG, European Spondyloarthropathy Study Group; pepA, peptide A; pepB, peptide B; RF, rheumatoid factor; RXJC, radiological joint count; SJC, swollen joint count 


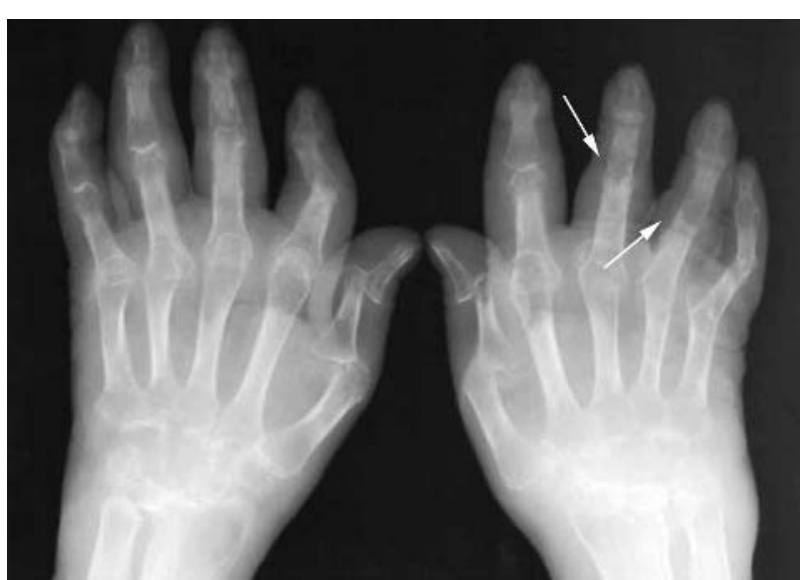

Figure 1 Radiographs of the hands of a patient with positive anti-cyclic citrullinated peptide antibodies (male, aged 68 years), showing ankylosis of different finger interphalangeal joints.

The clinical and radiological characteristics of the patients were obtained by retrospective analysis of the clinical records and review of the radiographs. A swollen joint count (SJC) was calculated at the sampling date; 74 joints were taken into account and included shoulders, elbows, wrists, metacarpophalangeal joints, temporomandibular joints, acromioclavicular joints, sternoclavicular joints, knees, ankles, tarsus, metatarsophalangeal joints, and all interphalangeal joints, counted as distinct units. Based on radiographs, the number of erosive or destructed hand or foot joints was calculated, taking into account the wrist, all metacarpophalangeal joints, the tarsus, all metatarsophalangeal joints, and all interphalangeal joints as distinct units (radiological joint count (RXJC), maximum 60). Enthesopathy, inflammatory back pain, and radiological sacroiliitis were defined according to the ESSG criteria for spondyloarthropathy, ${ }^{21}$ briefly summarised as follows:

- enthesopathy: past or present spontaneous pain or tenderness on examination of the site of the insertion of the Achilles tendon or plantar fascia;

- inflammatory back pain: history of or present symptoms of spinal pain in the back or neck meeting at least four of the following criteria: onset before age 45, insidious onset, improvement with exercise, association with morning stiffness, and of at least three months' duration;

- radiological sacroilitits: bilateral grade 2 or more or unilateral grade 3 or more.

Dactylitis was defined according to the definitions by Moll and Wright ${ }^{1}$ as follows: interphalangeal involvement with flexor tendon sheath effusion; pencil-in-cup phenomenon; arthritis mutilans. Ankylosis of small hand or foot joints was considered a typical radiological feature of psoriatic arthritis. ${ }^{4}$

\section{Anti-CCP antibodies}

Anti-CCP antibodies were detected by a commercially available ELISA containing synthetic peptides (Immunoscan rheumatoid arthritis, mark 2, Eurodiagnostica, Arnhem, Netherlands). The ELISA was carried out according to the manufacturer's instructions. Briefly, serum samples were diluted $1 / 50$ with dilution buffer and incubated for one hour at $37^{\circ} \mathrm{C}$. After removing the liquid and washing three times with rinsing buffer, the conjugate solution (peroxidase conjugated anti-human IgG antibodies) was added into each well and incubated for one hour at $37^{\circ} \mathrm{C}$. After three washing steps with rinsing buffer, the substrate solution (tetramethyl
Table 1 Patients and disease characteristics

\begin{tabular}{ll}
\hline Demographic features & \\
Sex (male/female ratio) & $111 / 81$ \\
Mean age (years) (range) & $47(16$ to 78$)$ \\
Mean disease duration (years) (range) & $10(0$ to 47$)$ \\
Familial psoriasis & $77 / 192(40 \%)$ \\
Familial IBD, PsA, or AS & $27 / 192(14 \%)$ \\
Actual use of DMARDs & $163 / 192$ \\
& \\
Clinical features & \\
Skin involvement & $172 / 192(90 \%)$ \\
Nail involvement & $105 / 192(55 \%)$ \\
Inflammatory low back pain & $76 / 192(40 \%)$ \\
DIP involvement & $75 / 192(39 \%)$ \\
Enthesitis & $84 / 192(44 \%)$ \\
Dactylitis & $78 / 192(41 \%)$ \\
Peripheral arthritis & $187 / 192(97 \%)$ \\
Persistent asymmetrical mono- or oligoarticular & \\
disease, predominantly of the lower limbs & $43 / 192(22 \%)$ \\
Radiological features & \\
Erosive disease & \\
Typical radiographic features & $64 / 139(46 \%)$ \\
Sacroiliitis & $23 / 139(16 \%)$ \\
Number of patients with at least one feature helpful in & $42 / 149(28 \%)$ \\
discriminating psoriatic arthritis from rheumatoid & \\
arthritis. & \\
&
\end{tabular}

AS, ankylosing spondylitis; DIP, distal interphalangeal joint; DMARD, disease modifying anti-rheumatic drug; IBD, inflammatory bowel disease; PsA, psoriatic arthritis.

benzidine) was added and incubated for 30 minutes at room temperature. The stop solution (sulphuric acid, $0.5 \mathrm{~mol} / \mathrm{l}$ ) was added and the absorbance values were read immediately at $450 \mathrm{~nm}$.

\section{Rheumatoid factor (RF)}

RF was determined by the latex fixation method. A suspension of uniform polystyrene particles sensitised in glycine buffer with heat altered human IgG (BD Diagnostic Systems, Sparks, Maryland, USA) was incubated with progressive dilutions of human sera in microtitre wells. After incubation, the plates were inspected for observable agglutination. The dilution titre present in the last well showing agglutination was recorded.

\section{Calculation of cut off points}

In an independent cohort of patients with inflammatory joint symptoms (containing only four patients with psoriatic arthritis), we previously defined cut off points for anti-CCP antibodies and RF as a function of a preset specificity level. ${ }^{18}$ For anti-CCP antibodies a cut off of $\geqslant 42 \mathrm{U} / \mathrm{ml}$ corresponded to a specificity of $\geqslant 98.5 \%(98.6 \% ; 95 \%$ confidence interval (CI), 95.8 to 99.8 ). For RF, a cut off of $\geqslant 160$ corresponded to a specificity of $\geqslant 95 \%$ (95.5\%; $95 \%$ CI, 91.7 to 99.3$)$. An RF titre of $\geqslant 1280$ corresponded to a specificity of $\geqslant 98.5 \%$ (98.6\%; 95\% CI, 95.8 to 99.8 ), comparable with the specificity of the anti-CCP test. ${ }^{18}$

\section{Anti-pepA and anti-pepB antibodies}

To confirm ACPA reactivity, anti-pepA and pepB antibodies were determined on all samples showing anti-CCP reactivity by a line immune assay (prototype of INNO-LIA ${ }^{\mathrm{TM}}$ rheumatoid arthritis, Innogenetics, Gent, Belgium), as described previously. ${ }^{14}$ This test detects antibodies against two synthetic citrullinated peptides, pepA and pepB. Previous studies indicated that the sensitivity and specificity of anti-pepA antibodies were, respectively, $63.4 \%$ and $>98.5 \%$ (100; $95 \%$ CI, 98.0 to 100), and the sensitivity and specificity of antipepB antibodies were $54 \%$ and $>98.5 \%$ (99.3; $95 \%$ CI, 96.8 to 100). ${ }^{14}$ Briefly, serum samples were diluted $1 / 100$ and incubated with the strip for one hour at room temperature. 


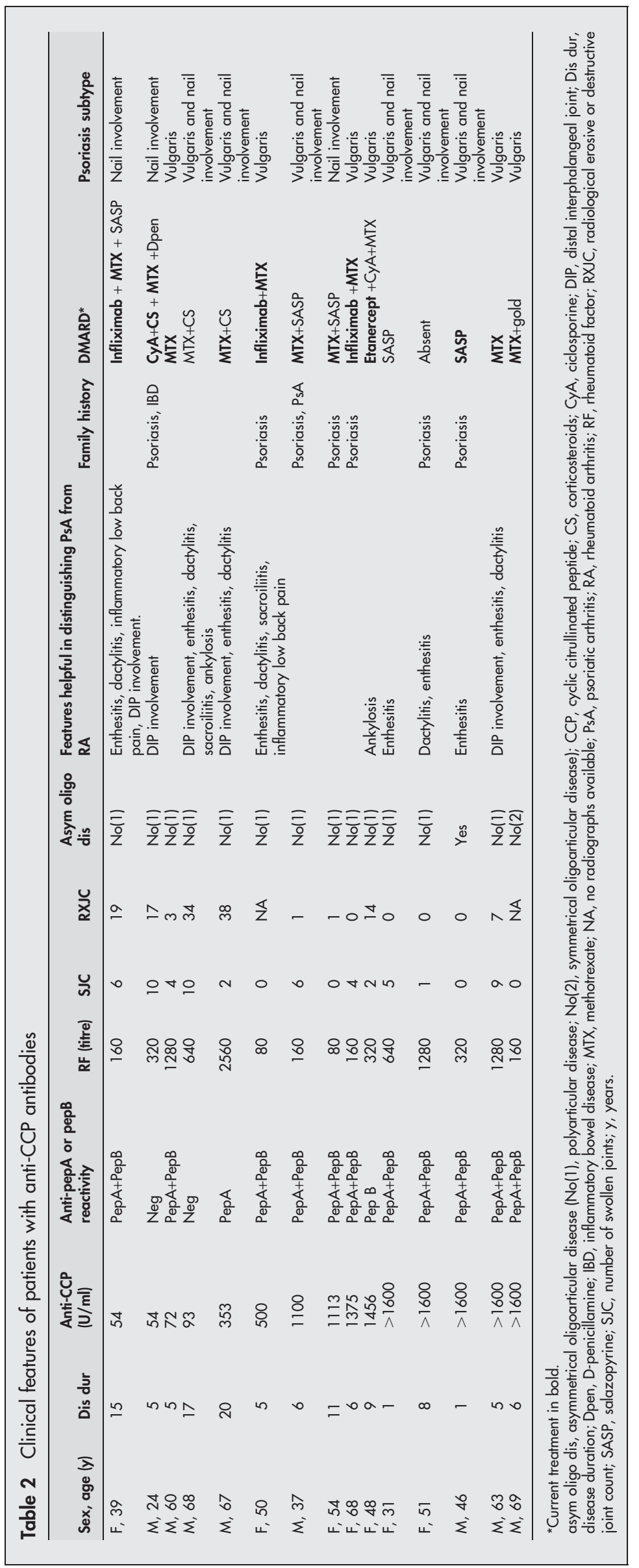

After aspirating the liquid and washing three times, the substrate solution NBT/BCIP (5bromo-4-chloro-3-indolyl phosphate/nitroblue tetrazolium) was added. The reaction was stopped in 0.1 M sulphuric acid and strips were dried. During each test, a reference cut off control strip was included, providing a cut off intensity for each antigen line. Tests were read visually by comparing the intensity of the test strip with the intensity obtained with the reference sample.

\section{Statistical analysis}

The Mann-Whitney U test was used to evaluate differences between groups,. Exact $\chi^{2}$ tests were computed for analysis of categorical data. We determined 95\% confidence intervals (CI) around specificities as described by Harper and Reeves. ${ }^{22}$ Statistical analysis was carried out using the Statistical Package for the Social Sciences (SPSS v12.0, Chicago, Illinois, USA).

\section{RESULTS}

Anti-citrullinated peptide antibodies and rheumatoid factor

Fifteen patients with psoriatic arthritis of the total cohort of $192(7.8 \%)$ had anti-CCP antibodies. In these 15 patients, ACPA reactivity was further confirmed with an independent citrullinated peptide substrate (pepA and pepB). Thirteen of 15 patients with anti-CCP reactivity had anti-pepA or anti-pepB reactivity (table 2 ).

Sixteen of 192 patients $(8.3 \%)$ were positive for RF at the cut off corresponding to the $95 \%$ specificity level. Three of these had no anti-CCP antibodies. At the $98.5 \%$ specificity level, we found that four patients $(2 \%)$ were positive for $\mathrm{RF}$, and all of these had anti-CCP antibodies.

\section{Clinical features of anti-CCP positive patients}

The clinical features of the patients with antiCCP antibodies are summarised in table 2 . Differences between patients with and without anti-CCP antibodies are indicated in table 3 . There were no major differences between the two patient groups for median disease duration or treatment. Patients with anti-CCP antibodies had a larger number of eroded joints (median 3 $v 0, \mathrm{p}=0.032$ ) but no significant difference in the swollen joint count at the date of sampling. There was no difference in the occurrence of typical radiological features or sacroiliitis. Of all patients with fewer than five affected joints (present or past and based on radiographs), 43 had predominantly lower limb involvement. Ten patients with anti-CCP antibodies had at least one feature suggested by McGonagle as being helpful in discriminating psoriatic arthritis from rheumatoid arthritis. ${ }^{4}$ These features comprise: asymmetrical oligoarticular disease, predominantly of the lower limbs; distal interphalangeal joint (DIP) involvement; enthesitis; dactylitis; typical radiological features (pencilin-cup phenomenon, ankylosis of small hand or foot joints, arthritis mutilans); radiological sacroiliitis; and inflammatory low back pain. 
Table 3 Comparison between CCP negative and CCP positive patients

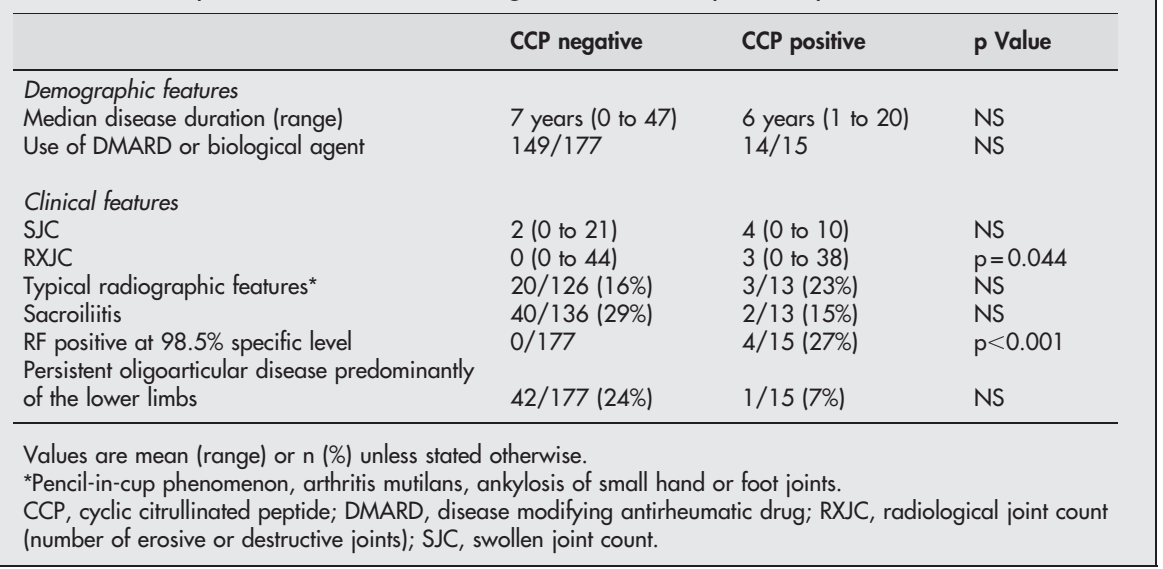

\section{Observed number of patients with anti-CCP antibodies $v$ expected number given the specificity of the test}

In a separate study, we calculated cut off points at a preset specificity level of at least $98.5 \%$ (a cut off of $42 \mathrm{U} / \mathrm{ml}$ for antiCCP antibodies). The corresponding specificity and 95\% CI were $98.6 \%(95.8 \%$ to $99.8 \%){ }^{18}$

In this cohort of 192 patients with psoriatic arthritis, we found $15(7.8 \%)$ with anti-CCP antibodies. This is more than expected in view of the specificity and 95\% CI obtained previously. Considering only those 10 patients with at least one feature suggested as helpful in distinguishing psoriatic arthritis from rheumatoid arthritis, ${ }^{4}$ there were still more patients with anti-CCP antibodies than expected (10 of 187; $5.3 \%)$.

\section{DISCUSSION}

In this study, we found that 15 of 192 patients $(7.8 \%)$ with psoriasis (skin or nail or both) and peripheral or axial arthritis had anti-CCP antibodies. This is more than would be expected in view of the high specificity of the test. PepA or pepB reactivity was confirmed in 13 of these 15 patients, pointing to specific anti-citrullinated peptide reactivity. Although patients with anti-CCP antibodies had a similar disease duration and similar treatment, they tended to have a higher radiological joint count than patients without antiCCP antibodies. Some also had rheumatoid factor. These data raise the question of whether positivity for anti-CCP antibodies in such patients is caused by the co-occurrence of rheumatoid arthritis and psoriasis. When we excluded the patients who did not have at least one feature helpful in discriminating between psoriatic arthritis and rheumatoid arthritis, ${ }^{4}$ and looked at differences in joint involvement, the patient subgroups were too small to reach significance (data not shown). It has been shown that patients who have antiCCP antibodies and who are also positive for the rheumatoid arthritis associated HLA shared epitope are at increased risk of developing rheumatoid arthritis (odds ratio $=66.8$ ). ${ }^{23}$ However, HLA data were not available in the present study.

The differential diagnosis between rheumatoid arthritis (in patients with psoriasis) and psoriatic arthritis may be difficult. $^{24}{ }^{25}$ Moll and Wright proposed that patients who are positive for rheumatoid factor should be considered to have rheumatoid arthritis, though they admitted that false positivity may occur. ${ }^{1}$ As RF is false positive in around $5 \%$ of healthy controls and in a larger proportion of patients with chronic diseases ${ }^{26}$ we did not exclude patients with a positive RF test at the standard cut off. Using a cut off at a higher specificity would reduce the number of false positive results. However, in the present study we found that one patient of the four with RF at the $98.5 \%$ specific cut off point had a disease picture that was not fully compatible with rheumatoid arthritis, while of the remaining three patients two had dactylitis, enthesitis, and DIP involvement-features that are typically attributed to psoriatic arthritis or spondyloarthropathy. ${ }^{21}$ Excluding patients who fulfil the ACR criteria for rheumatoid arthritis was not helpful either, as many patients with psoriatic arthritis fulfil those criteria. ${ }^{26}{ }^{27}$ Applying the ESSG criteria for spondyloarthropathy ${ }^{21}$ does not include the patients with a symmetrical pattern of arthritis that is indistinguishable from rheumatoid arthritis. A French group suggested a classification system based on weighted clinical, radiological, and HLA criteria. ${ }^{7}$ The major drawback of this classification system is the inclusion of HLA data. ${ }^{25}$ Also, in our present cohort, some psoriasis patients with dactylitiswhich is considered to be one of the most typical manifestations of psoriatic arthritis ${ }^{1}$ - did not fulfil those criteria. McGonagle et al suggested that one should consider all patients with arthritis and psoriasis or a familial history of psoriasis in combination with clinical or radiographic enthesitis, DIP disease, radiological sacroiliitis, uncommon arthropathies, dactylitis, monoarthritis, or asymmetrical oligoarthritis as having psoriatic arthritis. ${ }^{4}$ Patients with polyarticular disease without any of those features and without evidence of enthesitis on magnetic resonance imaging were considered to have rheumatoid arthritis. ${ }^{4}$ Using this algorithm, which needs to be validated further, we found that 10 patients showed at least one feature suggested by McGonagle to be helpful in discriminating psoriatic arthritis from rheumatoid arthritis. The number we thus obtain $(5.3 \%)$ is still higher than the $1.5 \%$ expected by the high specificity of the assay, obtained in an independent cohort. ${ }^{18}$

It is possible that some patients with typical psoriatic arthritis and positive anti-CCP or RF antibodies may have psoriatic arthritis patients with concomitant rheumatoid arthritis. ${ }^{4}$ This would presuppose a higher prevalence of rheumatoid arthritis in a psoriatic arthritis population than in the general population, in which it is estimated to be $1 \%$. Another possibility is that several psoriatic arthritis patients with anti-CCP antibodies had a disease picture that was not compatible with rheumatoid arthritis.

Our findings show that anti-CCP antibodies are more frequently present in a psoriatic arthritis population than in the populations generally used to assess the specificity of the test, such as healthy controls, patients with different rheumatic diseases, or patients with variant rheumatic complaints. Similarly, the presence of anti-CCP antibodies has also been described in patients with systemic lupus erythematosus $^{28} 29$ and primary Sjögren's syndrome. ${ }^{30}$ These 
findings raise other questions. Thus it could be hypothesised that reactivity for CCP could be a false positive, caused by reactivities to non-specific epitopes in the citrullinated peptide substrate. This phenomenon has been observed in animal models. ${ }^{31}$ However, we confirmed real ACPA reactivity with two independent synthetic citrullinated substrates (pepA and pepB), showing the presence of anti-pepA or pepB antibodies in 13 of the 15 psoriatic arthritis patients with anti-CCP antibodies. This supports the view that the observed CCP positivity was caused by genuine anticitrullinated peptide antibodies.

Another hypothesis could be that those patients with antiCCP antibodies suffer from an overlap with a preclinical form of rheumatoid arthritis. Indeed, anti-CCP antibodies may be present years before the clinical manifestation of rheumatoid arthritis. ${ }^{32}{ }^{33}$ Additionally, current DMARD treatment in those patients might prevent the full expression of rheumatoid arthritis. Thus, as suggested before, patients with anti-CCP antibodies require a cautious clinical and radiographic follow up to confirm the absence of future evolution to rheumatoid arthritis. $^{30}$

\section{Conclusions}

Our data suggest that anti-CCP antibodies may be present in patients with psoriatic arthritis Although it is possible that some of these patients have rheumatoid arthritis with concomitant psoriasis, in a proportion of them at least there are typical characteristics of psoriatic arthritis. The number of patients with psoriatic arthritis who have anti-CCP antibodies is greater than would be expected in view of the high specificity of the test.

\section{ACKNOWLEDGEMENTS}

Bert Vander Cruyssen is supported by a concerted action grant GOA $2001 / 12051501$ of the Ghent University, Belgium. Ilse Hoffman is supported by a research grant of the "Bijzonder Onderzoeksfonds", Ghent University. The work of Leen De Rycke is supported by the "Vlaams instituut voor de bevordering van het wetenschappelijktechnologisch onderzoek in de industrie" (IWT/ISB/11127). Dominique Baeten is a senior clinical investigator for the Fund for Scientific Research-Vlaanderen (FWO-Vlaanderen)

\section{Authors' affiliations \\ B V Cruyssen, I E A Hoffman, H Zmierczak, M Van den Berghe, \\ E Kruithof, L De Rycke, H Mielants, E M Veys, D Baeten, F De Keyser, Department of Rheumatology, Ghent University Hospital, 9000 Gent, Belgium}

\section{REFERENCES}

1 Moll JMH, Wright V. Psoriatic arthritis. Semin Arthritis Rheum 1973;3:55-78.

2 Marsal S, Armadans-Gil L, Martinez M, Gallardo D, Ribera A, Lience E. Clinical, radiographic and HLA associations as markers for different patterns of psoriatic arthritis. Rheumatology (Oxford) 1999:38:332-7.

3 Kane D, Stafford L, Bresnihan B, FitzGerald O. A classification study of clinical subsets in an inception cohort of early psoriatic peripheral arthritis - "DIP or not DIP revisited". Rheumatology (Oxford) 2003;42:1469-76.

4 McGonagle D, Conaghan P, Emery P. Psoriatic arthritis: a unified concept twenty years on. Arthritis Rheum 1999:42:1080-6.

5 Gladman D, Helliwell P, Mease PJ, Nash P, Titchlin C, Taylor W. Assessment of patients with psoriatic arthritis: a review of currently available measures. Arthritis Rheum 2004;50:24-35.

6 Veale D, Rogers S, FitzGerald O. Classification of clinical subsets in psoriatic arthritis. Br J Rheumatol 1994;33:133-8.

7 Fournie B, Crognier L, Arnaud C, Zabranieck L, Lascaux-Lefebvre V, Marc V, et al. Proposition de criteres de classification du rhumatisme psoriasique. Etude preliminaire de 260 patients. Rev Rhum (Ed Fr) 1999;66:513-24.

8 Taylor WJ, Helliwell PS. Development of diagnostic criteria for psoriatic arthritis: methods and process. Curr Rheum Rep 2004;6:299-305.
9 Koo T, Nagy Z, Sesztak M, Ujfalussy I, Meretey K, Bohm U, et al. Subsets in psoriatic arthritis formed by cluster analysis. Clin Rheumatol 2001;20:36-43.

10 Young BJJ, Mallya RK, Leslie RDG, Clarck CJM, Hamblin TJ. Anti-keratin antibodies in rheumatoid arthritis. BMJ 1979;2:97-9.

11 Girbal-Neuhauser E, Durieux J-J, Arnaud M, Dalbon P, Sebbag M, Vincent C, et al. The epitopes targeted by the rheumatoid arthritis-associated antifilaggrin autoantibodies are posttranslationally generated on various sites of (pro)filaggrin by deimination of arginine residues. J Immunol 1999; 162:585-94.

12 Schellekens GA, Visser H, de Jong BAW, van den Hoogen FHJ, Hazes JMW, Breedveld FC, Van Venrooij WJ. The diagnostic properties of rheumatoid arthritis antibodies recognizing a cyclic citrullinated peptide. Arthritis Rheum 2000:43:155-63.

13 Pinheiro CG, Scheinberg MA, Aparecida da Silva M, Maciel S. Anti-cyclic citrullinated peptide antibodies in advanced rheumatoid arthritis. Ann Intern Med 2003; 139:234-5.

14 Union A, Meheus L, Humbel RL, Conrad K, Steiner G, Moereels H, et al. Identification of citrullinated rheumatoid arthritis-specific epitopes in natural filaggrin relevant for antifilaggrin autoantibody detection by line immunoassay. Arthritis Rheum 2002;46:1185-95.

15 Hoffman IE, Peene I, Pottel H, Union A, Hulstaert F, Meheus L, et al. Diagnostic performance and predictive value of rheumatoid factor, anti-citrullinated peptide antibodies, and the HLA shared epitope for diagnosis of rheumatoid arthritis. Clin Chem, 2004, Sep 23 [Epub ahead of print].

16 Vallbracht I, Rieber J, Oppermann M, Forger F, Siebert U, Helmke K. Diagnostic and clinical value of anti-cyclic citrullinated peptide antibodies compared with rheumatoid factor isotypes in rheumatoid arthritis. Ann Rheum Dis 2004;63:1079-84.

17 Dubucquoi S, Solau-Servais E, Lefranc D, Marguerie L, Sibilia J, Goetz J, et al. Evaluation of anti-citrullinated fillagrin antibodies as hallmarks for the diagnosis of rheumatoid arthritis. Ann Rheum Dis 2004;63:415-19.

18 De Rycke L, Peene I, Hoffman I, Kruithof E, Union A, Meheus L, et al. Rheumatoid factor and anti-citrullinated protein antibodies in rheumatoid arthritis: diagnostic value, associations with radiological progression rate, and extra-articular manifestations. Ann Rheum Dis 2004;63:1587-93.

19 Lee DM, Schur PH. Clinical utility of the anti-CCP assay in patients with rheumatic diseases. Ann Rheum Dis 2003;62:870-4.

20 Suzuki K, Sawada T, Murakamani A, Matsui T, Tohma S, Nakazono K, et al. High diagnostic performance of ELISA detection of antibodies to citrullinated antigens in rheumatoid arthritis. Scand J Rheumatol 2003;32:197-204.

21 Dougados M, van der Linden S, Juhlin R, Huiffeldt B, Amor B, Calin A, et al. The European Spondyloarthropathy Study Group: preliminary criteria for classification of spondyloarthropathy. Arthritis Rheum 1991;34:1218-27.

22 Harper R, Reeves B. Reporting of precision of estimates for diagnostic accuracy: a review. BMJ 1999;318:1322-3.

23 Berglin E, Padyukov L, Sundin U, Hallmans G, Stenlund H, Van Venrooii WJ, et al. A combination of autoantibodies to cyclic citrullinated peptide (CCP) and HLA-DRB 1 locus antigens is strongly associated with future onset of rheumatoid arthritis. Arthritis Res Ther 2004;6:R303-8.

24 Palazzi C, Olivieri I, Petricca A, Salvarani C. Rheumatoid arthritis or psoritiatic symmetric polyarthritis? A difficult differential diagnosis. Clin Exp Rheumatol 2002;20:3-4

25 Helliwell PS. Relationship of psoriatic arthritis with the other spondyloarthropathies. Curr Opin Rheumatol 2004;16:344-9.

26 Arnett FC, Edworthy SM, Bloch DA, McShane DJ, Fries JF, Cooper NS, et al. The American Rheumatism association 1987 revised criteria for the classification of rheumatoid arthritis. Arthritis Rheum 1988;31:315-24.

27 Levin RW, Park J, Ostrov B, Reginato A, Baker DG, Bomalaski JS, Borofsky M, et al. Clinical assessment of the 1987 American College of Rheumatology criteria for rheumatoid arthritis. Scand J Rheumatol 1996;25:277-81.

28 Hoffman IEA, Peene I, Cebecauer L, Isenberg D, Huizinga T, Union A, et al. Presence of rheumatoid factor and antibodies to citrullinated peptides in systemic lupus erythematosus. Ann Rheum Dis 2005;64:330-2.

29 Mediwake R, Isenberg DA, Schellekens GA, van Venrooij WJ. Use of anticitrullinated peptide and anti-RA33 antibodies in distinguishing erosive arthritis in patients with systemic lupus erythematosus and rheumatoid arthritis. Ann Rheum Dis 2001;60:67-68.

30 Gottenberg JE, Migot S, Nicaise-Rolland P, Cohen-Solal J, Aucouturier F, Goetz J, et al. Prevalence of anti-cyclic citrullinated peptide and anti-keratin antibodies in patients with primary Siögren's syndrome. Ann Rheum Dis, 2004, Jul 1 [epub ahead of print].

31 Vossenaar ER, Van Boekel MA, van Venrooii WZ, Lopez-Hoyoz M, Merino J, Merino $R$, et al. Absence of citrulline-specific autoantibodies in animal models of autoimmunity. Arthritis Rheum 2004;50:2370-2.

32 Rantapaa-Dahlqvist S, de Jong BA, Berglin E, Hallmans G, Wadell G, Stenlund $\mathrm{H}$, et al. Antibodies against cyclic citrullinated peptide and IgA rheumatoid factor predict the development of rheumatoid arthritis. Arthritis Rheum 2003;48:2741-9.

33 Nielen MM, van Schaardenburg D, Reesink HW, van de Stadt RJ, van der Horst-Bruinsma IE, de Koning MH, et al. Specific autoantibodies precede the symptoms of rheumatoid arthritis: a study of serial measurements in blood donors. Arthritis Rheum 2004;50:380-6. 